SÁNCHEZ, Alcides Antúnez; VÁZQUEZ, Ana Elisa Gorgoso. El ecoturismo, influencia en el desarrollo sociocultural del municipio. Revista Eletrônica Direito e Política, Programa de Pós-Graduação Stricto Sensu em Ciência Jurídica da UNIVALI, Itajaí, v.16, n.2, $2^{\circ}$ quadrimestre de 2021. Disponível em: www.univali.br/direitoepolitica - ISSN 1980-7791.

\title{
EL ECOTURISMO, INFLUENCIA EN EL DESARROLLO SOCIOCULTURAL DEL MUNICIPIO
}

\author{
ECOTOURISM, INFLUENCE ON THE SOCIOCULTURAL DEVELOPMENT OF THE
}

MUNICIPALITY

\author{
Alcides Antúnez Sánchez ${ }^{1}$ \\ Ana Elisa Gorgoso Vázquez ${ }^{2}$
}

\section{RESUMEN}

El artículo hace una caracterización del desarrollo del ecoturismo en Cuba y su relación con el desarrollo sociocultural desde una perspectiva teórica doctrinal e histórica a nivel internacional. A partir del estudio de la legislación nacional que regula el ecoturismo y su impacto en el desarrollo cultural del municipio, asentado en el ordenamiento jurídico cubano. Se toma como muestra a la provincia Granma por la insuficiencia de regulaciones jurídicas que propicien la aplicación de esta práctica novedosa y espiritual para el desarrollo cultural. El turista busca no solo la calidad de los servicios turísticos, sino el contacto con la naturaleza y la adecuada conservación ambiental; la Organización Mundial de Turismo preconiza que una de las tendencias predominantes del turismo es el incremento de nuevas formas como es el turismo ecológico, necesitado de alcanzar una cultura adecuada para su protección. Son empleados los métodos como el de análisis histórico, el exegético, inducción deducción, y el jurídico comparado.

PALABRAS CLAVES: naturaleza, servicio turístico, patrimonio cultural, impacto.

\begin{abstract}
ABSTRAC
The article characterizes the development of ecotourism in Cuba and its relationship with sociocultural development from a doctrinal and historical theoretical perspective at the international level. Based on the study of the national legislation that regulates ecotourism and its impact on the cultural development of the municipality, established in the Cuban legal system. The Granma province is taken as a sample due to the insufficiency of legal regulations that promote the application of this novel and spiritual practice for

\footnotetext{
1 Máster en Asesoría Jurídica mención administrativo ambiental. Profesor Auxiliar Derecho Ambiental e Internacional Público en la Disciplina Derecho de la Economía. Facultad de Ciencias Económicas y Sociales. Universidad de Granma. República de Cuba. Email: aantunez@udg.co.cu ORCID No. 0000-0002-8561-6837

${ }^{2}$ Máster en Desarrollo Cultural Comunitario. Profesora Auxiliar en la carrera gestión sociocultural para el desarrollo. Facultad de Ciencias Económicas y Sociales. Universidad de Granma. República de Cuba. Email: agorgosov@udg.co.cu ORCID No. 0000-0001-8207-2902
} 
SÁNCHEZ, Alcides Antúnez; VÁZQUEZ, Ana Elisa Gorgoso. El ecoturismo, influencia en el desarrollo sociocultural del municipio. Revista Eletrônica Direito e Política, Programa de Pós-Graduação Stricto Sensu em Ciência Jurídica da UNIVALI, Itajaí, v.16, n.2, $2^{\circ}$ quadrimestre de 2021. Disponível em: www.univali.br/direitoepolitica - ISSN 1980-7791.

cultural development. The tourist seeks not only the quality of tourist services, but also contact with nature and adequate environmental conservation; The World Tourism Organization recommends that one of the predominant trends in tourism is the increase in new forms such as ecotourism, in need of achieving an adequate culture for its protection. Methods such as historical analysis, exegetical, induction deduction, and comparative legal analysis are used.

KEY WORDS: nature, tourist service, cultural heritage, impact.

MATERIALES Y MÉTODOS: El artículo tiene como objetivo caracterizar el desarrollo del ecoturismo en Cuba y su relación con el desarrollo sociocultural desde una perspectiva teórica doctrinal e histórica a nivel internacional. Se parte del estudio de la legislación nacional que regula el ecoturismo y su impacto en el desarrollo cultural del municipio, asentado en el ordenamiento jurídico cubano. Se toma como muestra a la provincia Granma para demostrar la insuficiencia de regulaciones jurídicas que propicien la aplicación de esta práctica novedosa y espiritual para el desarrollo sociocultural de los territorios que lo practican y de los que lo tienen en su estrategia de desarrollo local. Son empleados los métodos como el de análisis histórico, el exegético, inducción deducción, y el jurídico comparado.

\section{INTRODUCCIÓN}

Para muchas naciones subdesarrolladas como Cuba, el turismo es una actividad económica muy atractiva por el alto ingreso que genera en divisas, inversiones, empleos y activación de encadenamientos productivos que trae consigo. Sin embargo, la actividad turística estatal en Cuba ha seguido un criterio de planificación sectorial estatal, donde priman las relaciones verticales, ello constituye un reto en la actualización del modelo económico y social, a pesar de haber sido el destino número uno en el Caribe antes del triunfo de la Revolución en 1959. 
SÁNCHEZ, Alcides Antúnez; VÁZQUEZ, Ana Elisa Gorgoso. El ecoturismo, influencia en el desarrollo sociocultural del municipio. Revista Eletrônica Direito e Política, Programa de Pós-Graduação Stricto Sensu em Ciência Jurídica da UNIVALI, Itajaí, v.16, n.2, $2^{\circ}$ quadrimestre de 2021. Disponível em: www.univali.br/direitoepolitica - ISSN 1980-7791.

El sector turístico se ha convertido en la fuente de ingresos para muchos países del Caribe, con una gran competencia y calidad en el servicio turístico que comercializa, denominada como la economía azul. En el caso de Cuba, el turismo ha pasado a sustituir a la industria del azúcar como la principal fuente generadora de divisas. Por ello, la promoción turística cubana comercializa varios tipos de turismo, como: el de pesca, caza, buceo, aventura, turismo de salud, turismo náutico, el ecoturismo, el de sol y playa, y el cultural.

El 2002, Año Internacional del Turismo Ecológico, de acuerdo a la Declaración de Québec sobre el Turismo Ecológico, éste "...abraza los principios del turismo sostenible... Se adhiere asimismo a los principios específicos siguientes: contribuye activamente a la conservación del patrimonio natural y cultural; incluye a las comunidades locales e indígenas en su planificación, desarrollo y explotación y contribuye a su bienestar; interpreta el patrimonio natural y cultural del destino para los visitantes; se presta mejor a los viajeros independientes, así como a los circuitos organizados para grupos de tamaño reducido..."

La Organización Mundial del Turismo (OMT), se aprecia como cada vez más están arraigadas en turistas extranjeros las demandas relacionadas con la conservación del ambiente, la cultura y el arte, como la colaboración y compromiso en el desarrollo local.

Perón et al. (2000) junto con otros autores plantean que el desarrollo local en base a la actividad turística se considera multidimensional por tener injerencia o participación en los siguientes ámbitos: Económico: desarrollo de empresas, generación de empleos; Sociocultural: los valores sirven de base al desarrollo y a su vez se fortalecen; Político administrativo: los poderes locales son capaces de impulsar el desarrollo a través de la gestión de los recursos; Otras: tecnología, ambiental como lo es el desarrollo sostenible y en algunos casos la urbanística patrimonial

En consecuencia, el Turismo como actividad de ocio, requiere de la afluencia de diversas áreas productivas y de los sectores públicos y privados para proporcionar bienes y servicios demandados por los turistas a través del 
SÁNCHEZ, Alcides Antúnez; VÁZQUEZ, Ana Elisa Gorgoso. El ecoturismo, influencia en el desarrollo sociocultural del municipio. Revista Eletrônica Direito e Política, Programa de Pós-Graduação Stricto Sensu em Ciência Jurídica da UNIVALI, Itajaí, v.16, n.2, $2^{\circ}$ quadrimestre de 2021. Disponível em: www.univali.br/direitoepolitica - ISSN 1980-7791.

encadenamiento productivo. No tiene límites determinados ni un producto tangible o intangible, es la producción de servicios la que varía dependiendo del territorio a desarrollar. Uno de los puntos más controvertibles de la actividad turística es su capacidad de ser compatible con los modos de vida, naturaleza y cultura de las comunidades donde se desarrolle.

El artículo tiene como objetivo caracterizar el desarrollo del ecoturismo en Cuba y su relación con el desarrollo sociocultural desde una perspectiva teórica doctrinal e histórica a nivel internacional. Se parte del estudio de la legislación nacional que regula el ecoturismo y su impacto en el desarrollo cultural del municipio, asentado en el ordenamiento jurídico cubano. Se toma como muestra a la provincia Granma para demostrar la insuficiencia de regulaciones jurídicas que propicien la aplicación de esta práctica novedosa y espiritual para el desarrollo sociocultural de los territorios que lo practican y de los que lo tienen en su estrategia de desarrollo local.

La actualidad y pertinencia del tema se justiprecia que responde a la Política Económica y Social del Partido y la Revolución (PCC, 2011; PCC, 2016) aprobada en el VI, VII y VIII Congreso del Partido Comunista de Cuba de 2011, 2016, 2021 respectivamente. Donde se refiere en los lineamientos la prioridad de avanzar en los encadenamientos productivos, impulsar y fortalecer la base económica productiva de los municipios con la autonomía necesaria y la continuidad del desarrollo de la actividad no estatal como oferta turística complementaria.

\section{EL ECOTURISMO, DEFINICIÓN. ANTECEDENTES HISTÓRICOS}

El ecoturismo se ha convertido en una palabra de actualidad, aunque hay que precisar que existe poco consenso en la definición. En sus términos más generales, ecoturismo puede ser definido sobre la base de la naturaleza, el ambiente, un planteamiento verde, la ecología u otros campos relacionados que integran este concepto. 
SÁNCHEZ, Alcides Antúnez; VÁZQUEZ, Ana Elisa Gorgoso. El ecoturismo, influencia en el desarrollo sociocultural del municipio. Revista Eletrônica Direito e Política, Programa de Pós-Graduação Stricto Sensu em Ciência Jurídica da UNIVALI, Itajaí, v.16, n.2, $2^{\circ}$ quadrimestre de 2021. Disponível em: www.univali.br/direitoepolitica - ISSN 1980-7791.

El turismo ecológico, ecoturismo, turismo de naturaleza es un enfoque para las actividades turísticas en el cual se privilegia la preservación y la apreciación del ambiente, tanto natural como cultural, al acoger a los viajantes. Debido a su rápido crecimiento también se le ve como un subsector de la actividad turística.

En su acepción común la etiqueta ecoturismo implica un viaje ambientalmente responsable para disfrutar del medio natural y de la cultura de los habitantes, para promover la apreciación de las riquezas naturales y culturales de los lugares a visitar, da a la conservación un valor monetario tangible, que sirva de argumento para convencer tanto a los visitantes como a los lugareños de la importancia de la conservación de sus recursos culturales.

Aunque existen diferentes interpretaciones, por lo general se justiprecia por los articulistas que, el turismo ecológico se promueve como un turismo ético, en el cual se presume como primordial el bienestar de las poblaciones locales, y tal presunción por lo general se refleja en la estructura y funcionamiento de las empresas, grupos o cooperativas que se dedican a ofrecer este servicio turístico por sujetos estatales y privados concesionados para ejercitar esta actividad, vinculado al Derecho Administrativo.

El ecoturismo, en la bibliografía consultada, es apreciado como se le define como un viaje con un propósito determinado a zonas naturales, para el conocimiento de una cultura e historia natural del ambiente, cuidando y sin alterar la integridad del ecosistema, produciendo oportunidades económicas que hagan que las conservaciones de los recursos naturales beneficien a la población local.

Para la Sociedad Internacional de Ecoturismo (TIES) lo concibe como "...El viaje responsable en espacios naturales, que conserva el medio ambiente y mejora el bienestar de la población local..."

El concepto de ecoturismo se le atribuye a Ceballos Lascurain (1988) quien a finales de la década de los $80^{\prime}$ del pasado siglo XX expresara "...viajar a áreas naturales relativamente poco perturbadas o contaminadas, con el objetivo específico de estudiar, admirar, gozar los paisajes, su flora y fauna silvestres, así como cualquier manifestación cultural (tanto pasado como presente) encontrada 
SÁNCHEZ, Alcides Antúnez; VÁZQUEZ, Ana Elisa Gorgoso. El ecoturismo, influencia en el desarrollo sociocultural del municipio. Revista Eletrônica Direito e Política, Programa de Pós-Graduação Stricto Sensu em Ciência Jurídica da UNIVALI, Itajaí, v.16, n.2, $2^{\circ}$ quadrimestre de 2021. Disponível em: www.univali.br/direitoepolitica - ISSN 1980-7791.

en estas áreas. El turismo ecológico implica una apreciación científica, estética o filosófica, sin que el turista sea necesariamente un científico, artista o filósofo profesional..."

El ecoturismo, tuvo su origen en los inicios del turismo en el siglo XIX, cuando aparecieron destinos alejados del turismo de masas, caracterizados por tener una riqueza natural y entornos exóticos. Es un segmento de mercado que busca destinos alternativos, alejados del turismo de masas y focalizados principalmente en espacios naturales y culturales. Tiene como característica en promover la participación de la localidad en su gestión, de aquí su vínculo con el Derecho Laboral al generar empleos.

Relacionado con el ecoturismo se aprecia que se encuentra el senderismo, concebido como una actividad deportiva no competitiva, se realiza por caminos, sendas, preferentemente balizadas. Tiene como objetivo recuperar las antiguas sendas y caminos, mejorar la condición física y psicológica de quienes lo practican, por su vínculo con el Derecho Deportivo.

Con el fin de oponerse a la tendencia al turismo de masas, el ecoturismo se considera un valioso instrumento para la protección ecológica de zonas y especies sensibles, y para proporcionar una ayuda económica sostenible a comunidades que padecen de pobreza. Es adecuado para los países en desarrollo, con sus abundantes recursos naturales, y en especial para las montañas, que cada vez son objeto de mayor interés turístico, pero también son muy vulnerables al turismo.

Se valora por los articulistas que, el fomento del turismo sostenible satisface las necesidades de los turistas de hoy y de las regiones anfitrionas, a la vez protege e incrementa las oportunidades para el futuro. Se concibe dirigido a la gestión de todos los recursos de forma tal que las necesidades económicas, sociales y estéticas puedan satisfacerse y a la vez que se mantienen la integridad cultural, los procesos ecológicos esenciales, la diversidad biológica y los sistemas que sustentan la vida, ponderado con los Objetivos del Milenio a alcanzar para el 2030. 
SÁNCHEZ, Alcides Antúnez; VÁZQUEZ, Ana Elisa Gorgoso. El ecoturismo, influencia en el desarrollo sociocultural del municipio. Revista Eletrônica Direito e Política, Programa de Pós-Graduação Stricto Sensu em Ciência Jurídica da UNIVALI, Itajaí, v.16, n.2, $2^{\circ}$ quadrimestre de 2021. Disponível em: www.univali.br/direitoepolitica - ISSN 1980-7791.

Por ello, pese a la corta edad relativa de su existencia, el ecoturismo es visto por varios grupos conservacionistas, instituciones internacionales y gobiernos como una alternativa viable de desarrollo sostenible. "...Un desarrollo que satisface las necesidades del presente sin comprometer la capacidad de las generaciones futuras para satisfacer las suyas" (ONU). "Mejorar la calidad de vida humana sin rebasar la capacidad de carga de los ecosistemas que la sustentan". "La gestión y conservación de la base de recursos naturales y la orientación del cambio tecnológico para asegurar el logro y la continua satisfacción de las necesidades humanas para las generaciones presentes y futuras..." (FAO)

Al valorar la postura de Ceballos-Lascurain (1987), quien define al turismo de naturaleza o ecoturismo como "...la ejecución de un viaje a áreas naturales que están relativamente sin perturbar o contaminar, con el objetivo específico de estudiar, admirar y gozar el panorama junto con sus plantas $y$ animales silvestres y así mismo cualquier manifestación cultural, pasada y presente, que se encuentre en estas áreas..."

No obstante, se justiprecia que debe prestarse atención a que la fragilidad de los territorios que acogen estas modalidades es muy alta, tanto desde el punto de vista social como el ambiental. La práctica del ecoturismo ha demostrado que aún con ciertas concesiones a los vendedores mantienen condiciones mucho más favorables que los niveles de especulación actuales, buscan maximizar las ganancias en el menor tiempo posible, para después al comenzar el descenso de la rentabilidad producto de la degradación de los recursos, desplazar la inversión hacia otros lugares que ofrezcan posibilidades de lucro (Johansson, 1991), (Perkins, 1994), (Collins, 1999).

De aquí, que se pondere la definición de municipio turístico aportada por Sánchez y Fajardo (2004), lo entienden como aquel que posee una cierta relevancia turística al contar en su término municipal con recursos turísticos de una indudable capacidad de atracción de flujos corrientes de visitantes.

Los autores del artículo valoran que el turismo como fuente de desarrollo pretende no solo incrementar las oportunidades de generar riquezas económicas, sino que va mucho más allá, pues apunta a mejorar la calidad de vida de la 
SÁNCHEZ, Alcides Antúnez; VÁZQUEZ, Ana Elisa Gorgoso. El ecoturismo, influencia en el desarrollo sociocultural del municipio. Revista Eletrônica Direito e Política, Programa de Pós-Graduação Stricto Sensu em Ciência Jurídica da UNIVALI, Itajaí, v.16, n.2, $2^{\circ}$ quadrimestre de 2021. Disponível em: www.univali.br/direitoepolitica - ISSN 1980-7791.

población local, mediante la protección del medio de vida; mitigar los impactos adversos al ambiente, la generación de empleos, y fomentar el rescate del acervo patrimonial de la sociedad imbuida en este modelo de desarrollo local, al tributar al desarrollo endógeno y con ello al desarrollo humano en el municipio.

Considerando, las precisiones sobre la calidad como un requisito indispensable para el éxito del turismo ecológico. Según la OMT es "...la satisfacción de todos los requisitos y expectativas legítimos del cliente a un precio aceptable, de conformidad con los determinantes básicos de calidad como seguridad, higiene, accesibilidad de servicios turísticos y armonía con el entorno humano y natural..."

\section{EL TURISMO EN CUBA. BREVE ANÁLISIS DE SUS ORÍGENES Y TRACTO EVOLUTIVO}

Para este breve análisis histórico, se parte del inicio del turismo como una actividad económica, se sitúa en el tiempo a finales del XIX y comienzos del XX con la creación del organismo Ilamado Comisión Nacional de Fomento de Turismo (1919) en Cuba.

Para 1927 y 1928, Cuba se convierte en uno de los principales destinos turísticos del Caribe. En este mismo período se creó Cubana de Aviación como el turoperador aéreo, y en el 1930 se construye el Hotel Nacional y una serie de hoteles financiados por inversores extranjeros de la mafia italo norteamericana como el Habana Hilton, el Capri, el Habana Libre, el Habana Riviera a pesar de la crisis del 1929, denominada "Crack bancario" o "El jueves negro" la cual fue una de las caídas más devastadoras de la bolsa estadounidense que tuvo efecto mundial (Cirules, 2006).

En la zona del balneario de Varadero se construyeron los hoteles Oasis y el Internacional, y en la zona de Barlovento en la capital de Cuba, se construyó una marina. Además de un campo de golf de 18 hoyos en Colinas de Villareal en la propia capital. Al ser la nación cubana uno de los primeros destinos turísticos del Caribe en esta etapa (Cirules, 2006). 
SÁNCHEZ, Alcides Antúnez; VÁZQUEZ, Ana Elisa Gorgoso. El ecoturismo, influencia en el desarrollo sociocultural del municipio. Revista Eletrônica Direito e Política, Programa de Pós-Graduação Stricto Sensu em Ciência Jurídica da UNIVALI, Itajaí, v.16, n.2, $2^{\circ}$ quadrimestre de 2021. Disponível em: www.univali.br/direitoepolitica - ISSN 1980-7791.

Con la llegada del triunfo de la Revolución en 1959, con el cambio de sistema social, se comenzó a promover el nuevo proyecto social el turismo nacional y posteriormente el turismo internacional luego de la etapa de la nacionalización de las inversiones turísticas realizadas por extranjeros en el país, el gobierno utilizó como lema "Conozca a Cuba primero y al extranjero después". En este período se dispuso la creación con carácter autónomo y personalidad jurídica el Instituto Nacional de la Industria Turística. Luego esta actividad en su continuidad ha ido en evolución y desarrollo.

En consecuencia, se aprecia como en Cuba, el ecoturismo comienza de forma masiva en el ámbito nacional, a finales de la década de los 70' en el pasado siglo $\mathrm{XX}$, con la modalidad de campismo popular y en el campo internacional con la observación de aves a mediados de la década del 80'. Es importante señalar que los lugares escogidos para la práctica del campismo en el país, han estado situados fuera de las áreas que poseen altos valores ambientales, desde el punto de vista ecológico y de la biodiversidad; empero, a pesar de ello, el resultado en la conducta de los usuarios de este recurso, es un termómetro para reconocer por los articulistas que es insuficiente la capacidad administrativa y de instrucción de la educación ambiental, de aquí que se pondere la necesidad de la formación ambiental en pos de proteger el ambiente ante conductas irresponsables (Antúnez Sánchez, 2019).

En la continuación, en 1992 se crea el Grupo Nacional de Ecoturismo Ecológico, integrado por el Instituto Nacional de Turismo, Cubanacan S.A., el Grupo Gaviota, la Academia de Ciencias de Cuba, y la Comisión Nacional del Medio Ambiente, el Ministerio de la Agricultura, el Instituto de Planificación y Física y la Sociedad Espeleológica, quienes realizaron un examen de las principales zonas del país y se confeccionan de manera oficial las ofertas opcionales de visitas ecoturísticas. Por lo que se asevera que el ecoturismo tiene su desarrollo en la década de los 90'.

En 1994, se decide la constitución del Ministerio de Turismo (MINTUR) encargado de ejercer las funciones rectoras de la dirección política, regulación y control del sector y su actividad empresarial. Dirigiendo el proceso de desarrollo turístico 
SÁNCHEZ, Alcides Antúnez; VÁZQUEZ, Ana Elisa Gorgoso. El ecoturismo, influencia en el desarrollo sociocultural del municipio. Revista Eletrônica Direito e Política, Programa de Pós-Graduação Stricto Sensu em Ciência Jurídica da UNIVALI, Itajaí, v.16, n.2, $2^{\circ}$ quadrimestre de 2021. Disponível em: www.univali.br/direitoepolitica - ISSN 1980-7791.

mediante las empresas e instituciones relacionadas con los servicios afines a este tipo de demanda, logrando para este sector la competitividad global y eficiencia, garantizando su rentabilidad y sustentabilidad en el tiempo y su constante vínculo con la elevación del nivel y calidad de vida de los ciudadanos del país.

Luego en el devenir del tiempo, en la actividad administrativa por la Administración Pública, los ministerios de Ciencia y Tecnología y Medio Ambiente (CITMA), del MINTUR y la Agricultura (MINAGRI), emitieron una resolución conjunta que establecía las normativas generales para el desarrollo del turismo de naturaleza, se evidencia que su regulación es desde normativas administrativas internas. Requeridos al amparo de la Ley No. 81 de 1997, de una licencia ambiental para su explotación a través de una gestión ambiental adecuada por los actores autorizados.

En el escenario turístico nacional, se analiza como concurrió la comercialización ecoturística, la cual recae en instituciones que dependen del Estado como han sido las cadenas Horizontes Hoteles, Gaviota SA, Cubanacan SA, Havanatur S.A., Cubatur S.A., Rumbos, y ECOTUR, entre otras. Donde las mismas comercializan el producto ecoturismo y turismo de aventura por parte de sus turoperadores conformadas en el orden legal como sociedades mercantiles.

Otro actor en esta actividad del ecoturismo son los sujetos privados, dedicados a la renta de casas y otras actividades autorizadas, donde en muchas zonas de la geografía cubana se visualiza su práctica, regulada por el Ministerio de Trabajo y Seguridad Social (MTSS), como el organismo emisor de la licencia desde los 90'. Hay que destacar que, las instalaciones privadas favorecen el desarrollo de experiencias más auténticas en lo cultural y más ecológicas en lo ambiental para los turistas foráneos y cubanos.

Es algo valedero para la industria su humo, que el turismo mundial está creciendo, tanto en términos de número de viajeros como de expansión económica. Con este crecimiento viene la preocupación por los impactos ambientales y culturales asociados con el incremento. Diversos autores apoyan la noción de emprender un ecoturismo que ofrezca la oportunidad de proteger y conservar áreas naturales, al mismo tiempo que se aproveche del desarrollo 
SÁNCHEZ, Alcides Antúnez; VÁZQUEZ, Ana Elisa Gorgoso. El ecoturismo, influencia en el desarrollo sociocultural del municipio. Revista Eletrônica Direito e Política, Programa de Pós-Graduação Stricto Sensu em Ciência Jurídica da UNIVALI, Itajaí, v.16, n.2, $2^{\circ}$ quadrimestre de 2021. Disponível em: www.univali.br/direitoepolitica - ISSN 1980-7791.

económico y de la diversificación que el turismo puede conllevar a una comunidad a desarrollarle localmente, ello es una estrategia local de los gobiernos de los municipios para su desarrollo. Que permita revertir la imagen en el mundo que el turismo en la nación cubana no es solo sol y playa. Pero, esta requerido de una cultura en materia de ecoturismo, la que no está implementada de manera adecuada por el Estado, ya que este es un sector muy selectivo.

Todo ello ha motivado que, se haya convocado a toda la comunidad conservacionista, para que se tomen medidas adicionales y se elaboren estrategias nacionales, para evitar que experiencias similares ocurran en países donde se comienza a aplicar por primera vez. Surge entonces la expectativa de conciliar el desarrollo económico, con la conservación de los ecosistemas, como una concepción de sostenibilidad, requerida a consideración de los articulistas de una formación jurídica ambiental a los actores pasivos y activos que intervendrán (Antúnez Sánchez, 2019).

Hay que destacar que en la nación cubana se fomenta la preparación del capital humano que labora en estas instalaciones, los que reciben cursos de capacitación en las universidades en la carrera de Licenciatura en Turismo, concomitante a teoría del desarrollo local aplicada al turismo se inicia en la década del 90', con la confluencia de varios factores externos y comunes a otras actividades específicas del turismo en las Escuelas de Formación de Hotelería y Turismo (FORMATUR).

Permite a los articulistas analizar que, la relación entre estos conceptos ha sido formulada en algunos países y regiones, con la misma diversidad ideológica con que se identifica en la teoría del desarrollo local. Los municipios constituyen una cantera para el fomento de estas nuevas transformaciones. Identificada hoy en Cuba con el desarrollo del municipio en la actualización del modelo económico y social.

Estos elementos también, se aprecia que vincula con la Agenda 2030 para el desarrollo sostenible (objetivo 8, inciso 8.9) la cual plantea como propósito "de aquí a 2030, elaborar y poner en práctica políticas encaminadas a promover un turismo sostenible que cree puestos de trabajo y promueva la cultura y los productos locales" (ONU, 2015). 
SÁNCHEZ, Alcides Antúnez; VÁZQUEZ, Ana Elisa Gorgoso. El ecoturismo, influencia en el desarrollo sociocultural del municipio. Revista Eletrônica Direito e Política, Programa de Pós-Graduação Stricto Sensu em Ciência Jurídica da UNIVALI, Itajaí, v.16, n.2, $2^{\circ}$ quadrimestre de 2021. Disponível em: www.univali.br/direitoepolitica - ISSN 1980-7791.

\subsection{ECOTURISMO, REGULACIÓN EN EL ORDENAMIENTO JURÍDICO CUBANO}

En Cuba desde el triunfo de la Revolución en 1959, el Estado se ha preocupado por la protección ambiental, ha sido regulado desde el texto constitucional de 1976, su actualización en 2003, y en la nueva Constitución en 2019, donde en su artículo 75 se regula: Todas las personas tienen derecho a disfrutar de un medio ambiente sano y equilibrado. El Estado protege al medio ambiente y los recursos naturales del país. Reconoce su estrecha vinculación con el desarrollo sostenible de la economía y la sociedad para hacer más racional la vida humana y asegurar la supervivencia, el bienestar y la seguridad de las generaciones actuales y futuras.

También, en el artículo 79, se dispone: Todas las personas tienen derecho a participar en la vida cultural y artística de la nación. El Estado promueve la cultura y las distintas manifestaciones artísticas, de conformidad con la política cultural y la ley.

En el ordenamiento jurídico en su desarrollo, han sido promulgadas normas legales vinculantes al tema del artículo, como la Ley No 27 de 1980, Gran Parque Nacional Sierra Maestra, la que declara Zona Rural Protegida y, consecuentemente, de utilidad pública e interés social, la región montañosa conocida geográfica e históricamente con la denominación genérica de Sierra Maestra, que se extiende por la parte sudoriental del país en territorio de las provincias Granma, Santiago de Cuba y Guantánamo.

En su artículo 2, esta norma jurídica establece que la mencionada Zona Rural Protegida se denominará en lo adelante "Gran Parque Nacional Sierra Maestra" y su declaración como Zona Rural Protegida tiene el objetivo fundamental de proteger los valores histórico-culturales y naturales y el desarrollo integral y armónico del mismo, y como objetivos específicos los siguientes: destacar los sitios o lugares históricos, principalmente los de nuestra gesta libertadora a partir del año 1868; posibilitar la educación patriótica y ambiental, así como la investigación científica; proteger la flora, la fauna y el medio de todos los efectos nocivos que se derivan de cualesquiera acciones y omisiones o de vectores que puedan perjudicarlos; 
SÁNCHEZ, Alcides Antúnez; VÁZQUEZ, Ana Elisa Gorgoso. El ecoturismo, influencia en el desarrollo sociocultural del municipio. Revista Eletrônica Direito e Política, Programa de Pós-Graduação Stricto Sensu em Ciência Jurídica da UNIVALI, Itajaí, v.16, n.2, $2^{\circ}$ quadrimestre de 2021. Disponível em: www.univali.br/direitoepolitica - ISSN 1980-7791.

conservar los recursos hídricos; conservar y rehabilitar el suelo, y controlar la erosión y la sedimentación; incrementar la reforestación; conservar, proteger y enriquecer el paisaje; posibilitar la recreación y el turismo en sus más variadas formas; elevar el nivel socio-económico de la población; ajustar las producciones zonales a formas racionales y dinámicas de rendimientos sostenidos; y recuperar los recursos naturales renovables.

La Resolución No 17 de 1999, crea el Centro Nacional de Áreas Protegidas, adscrito a la Agencia de Medio Ambiente, perteneciente al Ministerio de Ciencia, Tecnología y Medio Ambiente (CITMA) tras su creación en 1995, el que tiene como misión ser el centro rector del planeamiento y gestión integral del Sistema Nacional de Áreas Protegidas, garantizando su dirección, control y óptimo funcionamiento; sus objetivos son: trabajar en coordinación con los organismos y órganos nacionales y territoriales y con otras dependencias de la Agencia de Medio Ambiente, así como promover la colaboración internacional en esta esfera con organizaciones afines, conforme le oriente la Dirección de Colaboración Internacional del Ministerio de Ciencia, Tecnología y Medio Ambiente.

En el Decreto Ley No 201 de 1999, del Sistema Nacional de Áreas Protegidas, tiene por objeto establecer el régimen legal relativo al Sistema Nacional de Áreas Protegidas, lo cual incluye las regulaciones del ejercicio de su rectoría, control y administración, las categorías de las áreas protegidas, su propuesta y declaración, el régimen de protección y el otorgamiento de las autorizaciones para la realización de actividades en dichas áreas.

La Ley No. 81 de 1997, establece dentro de sus artículos la Estrategia Ambiental, que tiene un desarrollo a nivel nacional y se expresa a nivel provincial y municipal, en pos de la preservación del ambiente cuando se ejecuta la herramienta de Evaluación de Impacto Ambiental para la inversión que se pretende ejecutar.

Es un hecho de que, Cuba cuenta con una abundante riqueza natural debido a su característica insular, mucha de esta riqueza sigue hoy en día totalmente "virgen", conservado precisamente, en muchas ocasiones, gracias al mismo embargo económico por parte de los Estados Unidos de América, otro elemento 
SÁNCHEZ, Alcides Antúnez; VÁZQUEZ, Ana Elisa Gorgoso. El ecoturismo, influencia en el desarrollo sociocultural del municipio. Revista Eletrônica Direito e Política, Programa de Pós-Graduação Stricto Sensu em Ciência Jurídica da UNIVALI, Itajaí, v.16, n.2, $2^{\circ}$ quadrimestre de 2021. Disponível em: www.univali.br/direitoepolitica - ISSN 1980-7791.

que se pueden destacar para demostrar el potencial ecoturístico del país es el elevado número de áreas protegidas con reconocimiento internacional. En este particular, se requiere potenciar la inversión extranjera en este sector, que complemente al turismo de sol y playa, a tenor con el cuerpo legal establecido en la Ley No. 118 de 2014, Ley de la Inversión Extranjera en su tracto evolutivo con sus normas antecesoras como el Decreto Ley No. 50 y la Ley No. 77.

También, en el ordenamiento legal se promulgó el Decreto Ley No. 200 de 1999, de las Contravenciones en materia de medio ambiente, para penalizar las infracciones administrativas que se cometan por los sujetos estatales y privados. La cual es concomitante con la ejecución de la función inspectiva, a tenor de la Resolución No. 103 de 2008 del CITMA, titulada Reglamento de la Inspección Estatal de la actividad Reguladora (Ramírez Sánchez y Antúnez Sánchez, 2019).

Otro cuerpo jurídico vinculado a esta actividad, se aprecia en la Ley No. 113 de 2012 , Ley Tributaria, donde aparece las políticas tributarias, arancelarias o de precios diferenciados para el desarrollo de actividades que incidan sobre el medio ambiente, como instrumento de la política y la gestión ambiental.

Dentro del régimen de sanciones administrativas en materia de protección ambiental es dictado por los Regímenes de Responsabilidad Administrativa, Civil y Penal, establecidos en la Ley No. 58 de 1987, Código Civil, en la Ley No. 7 de 1979, y en la Ley No. 62 de 19 Código Penal.

El MINTUR tiene como mandato, el incorporar en su actividad divulgativa y publicitaria la temática de protección en las áreas relacionadas con el ecoturismo, las áreas protegidas, la diversidad biológica, playas y áreas costeras y las aguas, haciendo énfasis en el manejo y gestión adecuadas del bioturismo en los aspectos ecológicos, culturales y sociales. En el acto administrativo interno de 2014, se disponen una serie de definiciones como:

Turismo de Naturaleza: La modalidad genérica que incluye varias tipologías específicas, que tienen como principal motivación la realización de actividades recreativas y de admiración, interpretación en áreas naturales relativamente poco alteradas, la vinculación con las comunidades y sus culturas locales. 
SÁNCHEZ, Alcides Antúnez; VÁZQUEZ, Ana Elisa Gorgoso. El ecoturismo, influencia en el desarrollo sociocultural del municipio. Revista Eletrônica Direito e Política, Programa de Pós-Graduação Stricto Sensu em Ciência Jurídica da UNIVALI, Itajaí, v.16, n.2, $2^{\circ}$ quadrimestre de 2021. Disponível em: www.univali.br/direitoepolitica - ISSN 1980-7791.

Ecoturismo: Modalidad turística especializada, ambientalmente responsable, consistente en visitar áreas naturales poco alteradas, con el fin de disfrutar, apreciar e interpretar los atractivos naturales (paisaje, flora y fauna silvestres, entre otros) de dichas áreas, así como cualquier manifestación cultural, del presente y del pasado, que puedan encontrarse ahí, a través de un proceso que promueve la conservación, tiene bajo impacto ambiental y cultural y propicia un involucramiento activo y socioeconómicamente beneficioso para las poblaciones locales.

Turismo de Aventuras: Toda actividad turística que implica determinado esfuerzo físico para cumplimentar el reto y el desafío, con el uso de equipamiento o no y sobre la base del riesgo controlado y la seguridad del turista, sin degradar o agotar los recursos y el medio ambiente.

Actividades que se concretan luego de analizar el ordenamiento jurídico en el turismo a través de contratos mercantiles conforme a la norma legal que lo regula en el Derecho Mercantil entre las partes involucradas sobre el producto turístico a comercializar gestionado por el sector estatal y el privado.

Demuestra a los articulistas que por la característica de ser multitransdisciplinario, el ecoturismo guarda relación con el Derecho Internacional, el Derecho Constitucional, el Derecho Administrativo, el Derecho Mercantil, el Derecho Civil, el Derecho Agrario, el Derecho Tributario, la Informática Jurídica, entre otras. Pero se vincula con otras ciencias como la Geografía, la Historia, la Economía, la Contabilidad, entre otras. El mismo su sustento legal está dispuesto en acto administrativo interno por el MINTUR.

Esta forma de actividad turística, se aprecia que es realizada por personas que viajan con la motivación de contemplar la naturaleza y su disfrute. Son viajeros que desean alejarse de las destinaciones típicas del turismo de masas, conocer nuevos lugares y disfrutar nuevas experiencias. Estos turistas tienen una concienciación ambiental, respeto por las culturas y las comunidades locales más alta que el resto de los turistas lo cual hace que estos sean unos turistas muy particulares. El período de duración oscila entre 5 a 7 días, el que puede cambiarse en su extensión de más días con opciones de sol y playa. 
SÁNCHEZ, Alcides Antúnez; VÁZQUEZ, Ana Elisa Gorgoso. El ecoturismo, influencia en el desarrollo sociocultural del municipio. Revista Eletrônica Direito e Política, Programa de Pós-Graduação Stricto Sensu em Ciência Jurídica da UNIVALI, Itajaí, v.16, n.2, $2^{\circ}$ quadrimestre de 2021. Disponível em: www.univali.br/direitoepolitica - ISSN 1980-7791.

\subsection{El ecoturismo, desarrollo y evolución en la provincia Granma}

La provincia Granma, es una región geográfica distribuida en dos grandes regiones naturales, una es la Llanura del Cauto, de las más extensas del país, del grupo orográfico Sierra Maestra, con alturas superiores a los 1700 metros sobre el nivel del mar, en el que resalta el Pico Real del Turquino con 1792 metros sobre el nivel medio del mar. Dispone de 260 kilómetros de litoral y alrededor de las dos terceras partes son costas bajas del Golfo de Guacanayabo, el resto son costas acantiladas y profundas del litoral Sur. Además, existen unos $9,7 \mathrm{~km}^{2}$ de cayos, por lo general pequeños y de difícil utilización en actividades económicas, con excepción de las labores de apoyo a la pesca.

En este territorio analizado, se concentra un volumen considerable de valores potenciales con fines turísticos para la región, situados a lo largo y ancho de la costa Sur y el territorio montañoso que constituye la Sierra Maestra. Estos recursos naturales y antrópicos abarcan las más disímiles potencialidades, desde playas en litoral y en la cayería cercana, hasta ríos con posibilidades para el baño, paisajes con alto valor estético, parques nacionales con incontables recursos de gran riqueza natural, vías escénicas, lagunas y presas, saltos de agua, áreas de caza, cuevas de reconocido valor científico, yacimientos de aguas y fangos mineromedicinales, fondos submarinos $y$ existencia de climas confortables en las alturas, a los 600 metros sobre el nivel del mar.

Los diferentes escenarios de carácter histórico cultural es otro de los recursos de gran importancia por los que son conocidos la montaña y el llano granmense. El área geográfica de la costa sur de la provincia abarca unos $440 \mathrm{Km}^{2}$ conformando una región turística que se extiende desde Cabo Cruz hasta El Río Macío, denominada Región Turística Sur de Granma, de la que forman parte 4 de los 6 polos turísticos dentro del territorio. Estos polos son Cabo Cruz, Punta de Hicacos, Marea del Portillo y El Macío. Fuera de la región turística se localizan los polos turísticos de Bayamo y Virama.

Por lo que se justiprecia que la provincia Granma cuenta con un indiscutible potencial para el desarrollo del turismo de naturaleza, el cual se valora que no ha 
SÁNCHEZ, Alcides Antúnez; VÁZQUEZ, Ana Elisa Gorgoso. El ecoturismo, influencia en el desarrollo sociocultural del municipio. Revista Eletrônica Direito e Política, Programa de Pós-Graduação Stricto Sensu em Ciência Jurídica da UNIVALI, Itajaí, v.16, n.2, $2^{\circ}$ quadrimestre de 2021. Disponível em: www.univali.br/direitoepolitica - ISSN 1980-7791.

sido suficientemente explotado en algunas zonas y en otras, la mayor parte, aún permanecen vírgenes, pudiendo ser una oferta única por contar con un fuerte contraste de playa-montañas con un alto endemismo en la flora y la fauna. La existencia de parques nacionales y complejos naturales de grandes valores con destacados recursos en la fauna, la flora, geomorfología y otros elementos relevantes desde el punto de vista natural y paisajístico, permitirían con un adecuado proceso inversionista, el desarrollo de las potencialidades del turismo relacionado con la naturaleza, lo que a su vez coadyuvaría a elevar el nivel y calidad de protección, conservación y uso racional de estos recursos, que con carácter de política de Estado desempeñan un conjunto de organismos y entidades del país, y muy especialmente la Empresa Nacional para la Conservación de la Flora y la Fauna.

Entre la gama de potenciales y opciones relacionadas con el turismo ecológico que existen en nuestra provincia se pueden mencionar las siguientes:

Ecoturismo Especializado: Senderismo en las modalidades de caminatas, caballo y mulo, Práctica del Alpinismo en terrazas cársicas, Observación de la flora y la fauna, Campismo y excursiones en tierra firme y cayería adyacente a lugares seleccionados por su interés ecológico, científico, histórico, social y económico, Observación y caza de aves cinegéticas, Pesca deportiva de la trucha en lagunas y presas con carrete manual, Buceo y foto submarina en terrazas marinas y barreras coralinas, Foto-caza ecológica.

Ecoturismo de Aventuras y Recreación: Buceo en aguas profundas y cavernas, Buceo con snorteling, Caza de cocodrilos, Desplazamiento en delta planos, Sky acuático, Windsurfing, Recorridos en kayacs de una y dos plazas en ríos, presas y mar, Alpinismo, Espectáculo de ferias agropecuarias con eventos de rodeo, equitación, competencias ecuestres, exposición de ganado mayor y menor, topes de gallos de lidia, etc. Disfrute de baños en playas y ríos, Práctica de hipismo.

Ecoturismo Científico: Investigación sobre la flora y la fauna, Eventos científicos, Arqueología, Instalación para congresos, conferencias, etc. 
SÁNCHEZ, Alcides Antúnez; VÁZQUEZ, Ana Elisa Gorgoso. El ecoturismo, influencia en el desarrollo sociocultural del municipio. Revista Eletrônica Direito e Política, Programa de Pós-Graduação Stricto Sensu em Ciência Jurídica da UNIVALI, Itajaí, v.16, n.2, $2^{\circ}$ quadrimestre de 2021. Disponível em: www.univali.br/direitoepolitica - ISSN 1980-7791.

Ecoturismo de Salud: Tratamiento con aguas y fangos mineromedicinales y termales en instalaciones especializadas integradas al entorno natural.

Ecoturismo Histórico-Cultural: El medio en que se desarrolla el turismo ecológico es parte integrante e inseparable del turismo histórico pues ha sido activo testigo desde la época precolombina del desarrollo y más tarde del exterminio de nuestra cultura aborigen hasta la gesta libertaria iniciada por Carlos Manuel de Céspedes, en su ingenio "La Demajagua" el 10 de Octubre de 1868 y culminada por el Comandante en Jefe Fidel Castro Ruz el 1ro de Enero de 1959, con la total independencia del pueblo cubano. En este marco es posible revivir, entre otros, los hechos del Guafe, la Demajagua, Dos Ríos, Las Coloradas, Cinco Palmas y La Comandancia de La Plata.

De los lugares vinculados a la historia nacional, que son priorizados en su protección en el ordenamiento jurídico a tenor de la Ley No.1 de 1977, Ley de Protección al Patrimonio Cultural, su estudio, acondicionamiento y propuesta de explotación turística están en estrecha relación con el turismo de naturaleza se conciben la zona del Dátil y Peralejo, en el municipio Bayamo, La Jatía, Dos Ríos y La Rinconada, en el municipio Jiguaní. La Demajagua, en el municipio Manzanillo. Las Coloradas, Alegría de Pío y El Guafe, en el municipio Niquero. Cinco Palmas, en el municipio Media Luna. La Comandancia de La Plata, en el municipio Bartolomé Masó. Boca del Toro, en el municipio Pilón. Loma de Piedra (Monumento a Braulio Coroneaux) y Pino del Agua, en el municipio Guisa. La zona del asesinato de Juan Manuel Marqués, en el municipio Campechuela. Pata de la Mesa y El Hombrito, en el municipio Buey Arriba.

Ecoturismo Social: Recorridos e intercambios con pobladores y personalidades de comunidades serranas y costeras creadas por la Revolución, Festival Artístico con el Órgano Oriental, Participación en Jornadas Culturales, visitas por la casa museo del Padre de la Patria en Bayamo, a la Casa de la nacionalidad en el municipio Bayamo, el Museo de Cera en el municipio Bayamo.

Turismo histórico-cultural: En la zona de Coloradas se produjo el 2 de diciembre de 1956 el desembarco de los expedicionarios del yate Granma para dar inicio a uno de los episodios más significativos de la historia cubana. Del período colonial 
SÁNCHEZ, Alcides Antúnez; VÁZQUEZ, Ana Elisa Gorgoso. El ecoturismo, influencia en el desarrollo sociocultural del municipio. Revista Eletrônica Direito e Política, Programa de Pós-Graduação Stricto Sensu em Ciência Jurídica da UNIVALI, Itajaí, v.16, n.2, $2^{\circ}$ quadrimestre de 2021. Disponível em: www.univali.br/direitoepolitica - ISSN 1980-7791.

español queda en perfectas condiciones y aún en uso, un faro del siglo pasado, el faro Vargas (Cabo Cruz).

Además, existen amplias evidencias de población aborigen en estos territorios por grupos agro alfareros y preabro alfareros que se manifiestan en distintos sitios arqueológicos como El Guafe con cuevas ceremoniales y funerarias y un extenso sitio habitacional en los cuales existen 7 ídolos, entre los que se destaca el Ídolo del Agua, posible representación de la deidad antillana Atabeira. Para la actividad específica de caza menor se propone la zona de las arroceras de Yara y Manzanillo.

No cabe dudas, que el turismo cultural va adquiriendo una significativa importancia, lo que obliga a pensar en su utilidad económica, pero también en desarrollarlo sobre bases sustentables para que la cultura siga siendo una herencia del patrimonio y la identidad de cada comunidad para el disfrute de las generaciones futuras, involucra, además, el pleno respeto y aplicación de los principios adoptados por la UNESCO y sus agencias como el Consejo Internacional de Monumentos y Sitios (ICOMOS) que en 1976 adoptó la Carta del Turismo Cultural donde el principio de la sustentabilidad constituye una bandera a defender por el turismo y por la cultura. Sustentado en el Código Ético Mundial para el Turismo, es el marco normativo de referencia cuando se discute sobre turismo responsable y sostenible. Fue aprobado en 1999 por la Asamblea General de la OMT.

El turismo sostenible, es aquel que tiene concebido las consecuencias económicas, sociales y ambientales presentes y futuras del desarrollo de sus actividades, enfocándose en complacer las exigencias de los turistas, la industria, el planeta y las poblaciones residentes en estos lugares (OMT, 2017).

El turismo responsable, se entiende como cualquier modalidad de turismo que implique una explotación del mismo más responsablemente. El turismo responsable reduce los efectos sociales, económicos y ambientales nocivos de la actividad turística, incrementando los ingresos económicos de las comunidades de acogida (OMT, 2017). 
SÁNCHEZ, Alcides Antúnez; VÁZQUEZ, Ana Elisa Gorgoso. El ecoturismo, influencia en el desarrollo sociocultural del municipio. Revista Eletrônica Direito e Política, Programa de Pós-Graduação Stricto Sensu em Ciência Jurídica da UNIVALI, Itajaí, v.16, n.2, $2^{\circ}$ quadrimestre de 2021. Disponível em: www.univali.br/direitoepolitica - ISSN 1980-7791.

El turismo cultural y cultural-cognitivo en realidad se puede significar que es la forma de turismo, que se centra en el entorno cultural, que a su vez pueden incluir lugares culturales e históricos de un destino o el patrimonio históricocultural, los valores y estilo de vida de los locales de población, las artes, la artesanía, las tradiciones y costumbres de la población local. Es un instrumento para el desarrollo económico que logra el crecimiento económico mediante la atracción de visitantes fuera de la comunidad huésped, que están motivados general o parcialmente por un interés en el contexto histórico, artístico, científico o aspectos del estilo de vida y las tradiciones, realidad y hechos de una comunidad, región, grupo o institución, donde la provincia Granma precia de tener mucha potencialidad en este particular (Gorgoso Vázquez y Antúnez Sánchez, 2021).

En este sentido, el intelectual Fernando Ortiz (1983), jurista devenido antropólogo y filósofo de la cultura, perteneció a ese prolífero y rico mundo de la cultura cubana, durante las décadas del 30 y el 40 del siglo XX explicaba desde sus aportes el concepto integral de cultura, decía "...el dominio de la naturaleza sería insuficiente y hasta parcialmente infausto, pese a sus maravillosos adelantos materiales, si la misma ciencia, aplicada a las culturas humanas, no fuera la que en definitiva señalara las verdaderas e inexcusables necesidades de todos los pueblos y estudiara sus potencialidades de trabajo, organización e intercambio, sus deficiencias y cómo corregirlas, la mejor distribución de los recursos globales y la capacitación de las gentes para realizar los progresos de todo orden que van mejorando la vida integralmente: todo ello articulado en lo posible a las respectivas condiciones culturales, tradiciones, costumbres y apetencias razonables..."

Estos elementos abordados, permiten a los articulistas ponderar la necesidad de que se retomen los estudios universitarios de la carrera de Licenciatura en Turismo en la Universidad de Granma, la que en su momento era parte de las carreras objeto de estudio en este centro académico en una provincia con potencialidad para desarrollar el ecoturismo. Donde las carreras de Gestión Sociocultural para el desarrollo y la de Derecho tienen contenidos a impartir en el proceso formativo. 
SÁNCHEZ, Alcides Antúnez; VÁZQUEZ, Ana Elisa Gorgoso. El ecoturismo, influencia en el desarrollo sociocultural del municipio. Revista Eletrônica Direito e Política, Programa de Pós-Graduação Stricto Sensu em Ciência Jurídica da UNIVALI, Itajaí, v.16, n.2, $2^{\circ}$ quadrimestre de 2021. Disponível em: www.univali.br/direitoepolitica - ISSN 1980-7791.

\subsection{Limitantes en el ordenamiento jurídico cubano vinculados a la actividad turística}

Al realizar una revisión en el ordenamiento jurídico cubano, se constata lagunas normativas en cuanto a:

-No existe una Ley orgánica de Turismo que reconozca dentro de sus articulados la personalidad jurídica de los municipios turísticos ni la autonomía municipal en materia de gestión turística, que les permita empoderarse de esta gestión para potenciar el desarrollo local y con ello tribute a la competencia.

-No existe una Ley de Municipio, donde el gobierno local tenga competencias en las relaciones de la gestión de los destinos turísticos, la capacidad normativa en materia tributaria, en la implementación de la política turística, competencias decisorias en el destino turístico, la creación de servicios públicos destinados al turismo por cada gobierno local, se delimiten los límites en la actuación del MINTUR y los gobiernos locales

-Ausencia de una Ley de Empresas, donde se delimite la actuación de los sujetos económicos estatales y los privados en la gestión turística, en atención a los tipos de propiedad reconocidos en el texto constitucional de 2019.

-Se requiere la actualización de la Ley No. 81, Ley del Medio Ambiente por su vínculo con la protección ambiental y el patrimonio

-Se requiere de una norma legal sobre el emprendimiento, en particular al sector turístico por sujetos privados.

-Inexistencia de una norma jurídica sobre la protección a la biodiversidad

\section{CONCLUSIONES}

El turismo, en la caracterización realizada ha permitido señalar que la dimensión ambiental es uno de los núcleos duros en el desarrollo económico social hacia el 2030 en Cuba. Tiene un carácter transversal al estar presente en la mayoría de las actividades del país, como son las políticas públicas destinadas al desarrollo 
SÁNCHEZ, Alcides Antúnez; VÁZQUEZ, Ana Elisa Gorgoso. El ecoturismo, influencia en el desarrollo sociocultural del municipio. Revista Eletrônica Direito e Política, Programa de Pós-Graduação Stricto Sensu em Ciência Jurídica da UNIVALI, Itajaí, v.16, n.2, $2^{\circ}$ quadrimestre de 2021. Disponível em: www.univali.br/direitoepolitica - ISSN 1980-7791.

local del municipio. En Cuba está centrada al sol y playa, con un turismo masivo, aun sin tener en cuenta la alternativa del ecoturismo.

El municipio y el ecoturismo como parte de las políticas públicas dirigidas al desarrollo local son pertinentes para la protección de la biodiversidad, al cambio climático y la calidad ambiental establecidos en la Estrategia Ambiental Nacional del Ministerio de Ciencia, Tecnología y Medio Ambiente en Cuba, aun sin alternativas adecuadas que permitan su despegue, complementando al turismo masivo que se comercializa de sol y playa, donde participen actores estatales y privados en pos de avanzar en el desarrollo de la economía azul.

Las insuficiencias en el ordenamiento jurídico permiten señalar que hay que fortalecer el marco institucional y jurídico con normativas que eliminen las lagunas juridicas detectadas para su perfeccionamiento vinculadas al ecoturismo como alternativa al turismo del Sol y Playa en atención a su transversalidad.

En la universidad de Granma, se precisa restablecer la carrera de Licenciatura en Turismo, ello tributará a fortalecer la educación, la conciencia y la cultura ambiental en pos de la sostenibilidad económico-financiera para el desarrollo del municipio que le permita alcanzar un desarrollo ecológicamente equilibrado, socialmente justo y económicamente sostenible.

\section{REFERENCIAS DE LAS FUENTES CITADAS}

Agenda 2030 (2018) Los objetivos de desarrollo sostenible. Una oportunidad para América Latina y el Caribe. Chile: CEPAL.

Ayala, H. (2001) Medio siglo de transformaciones del Turismo en Cuba. Universidad de La Habana.

Ayala, H. (2007) Modalidades turísticas, características y situación actual, Universidad de La Habana.

Álvarez Berovides, M. et al. (2016) Los estudios de las políticas culturales, Cienfuegos: Universo Sur. 
SÁNCHEZ, Alcides Antúnez; VÁZQUEZ, Ana Elisa Gorgoso. El ecoturismo, influencia en el desarrollo sociocultural del municipio. Revista Eletrônica Direito e Política, Programa de Pós-Graduação Stricto Sensu em Ciência Jurídica da UNIVALI, Itajaí, v.16, n.2, $2^{\circ}$ quadrimestre de 2021. Disponível em: www.univali.br/direitoepolitica - ISSN 1980-7791.

Almanza Olmo, S. y Sierra, M. (2004) Cultura cubana siglo XX. La Habana: Félix Varela.

Almanza Olmo, S. y Torres Moré, P. (2006) Panorama de la cultura cubana. Antología. La Habana: Félix Varela.

Antúnez Sánchez, A. (2017) La inspección ambiental, la evaluación de impacto ambiental, la autorización ambiental y la auditoría ambiental. Revista de Derecho Público Iberoamericano Nº. 10. Chile.

Antúnez Sánchez, A. (2018) La formación ambiental. Una necesidad en el siglo XXI con el nuevo saber ambiental, Revista Murmullos del Sur, UNAM, México.

Antúnez Sánchez, A. et al. (2015) El turismo de naturaleza, su impacto ambiental en torno a la protección del medio ambiente. Contexto Cubano en el siglo XXI. Perspectivas futuras en la provincia Granma. Revista Ámbito Jurídico. Brasil.

Aguiló-Pérez, E. \& Matos Da Silva, J. (2015) Encyclopedia of Tourism. Springer International Publishing.

Arjona, M. (1986) Patrimonio cultural e identidad nacional. La Habana: Letras Cubanas.

Barnet, M. (1995) Cultos afrocubanos: La regla de Ocha, la regla de Palo Monte. La Habana: Unión

Benítez, D. et al. (2010) Derecho del Turismo Iberoamericano. España: Tirand Lo Blanch.

Castro Ruz, F. (1987) Palabras a los Intelectuales. En Pensamiento y política cultural cubanos. La Habana: Pueblo y Educación.

Cirules, E. (2006) La vida secreta de Meyer Lansky en La Habana. La Habana: Ciencias Sociales. 
SÁNCHEZ, Alcides Antúnez; VÁZQUEZ, Ana Elisa Gorgoso. El ecoturismo, influencia en el desarrollo sociocultural del municipio. Revista Eletrônica Direito e Política, Programa de Pós-Graduação Stricto Sensu em Ciência Jurídica da UNIVALI, Itajaí, v.16, n.2, $2^{\circ}$ quadrimestre de 2021. Disponível em: www.univali.br/direitoepolitica - ISSN 1980-7791.

Ceballos Lascuráin, H. (1998) Ecoturismo. Naturaleza y Desarrollo Sostenible, $1^{\text {ra }}$ edición, México: Diana.

Ceballos-Lascurain, H. (1987) Estudio de Perfectibilidad Socioeconómica del Turismo Ecológico y Anteproyecto arquitectónico y urbanístico del Centro de Turismo Ecológico de San Kalan, México: SEDUE.

Correa Escribano, M. et al. (2017) La cadena productiva del ecoturismo como contribución al desarrollo local. Revista Retos de la Dirección No.1. Universidad de Camagüey.

Correa, E. et. al (2015) Consideraciones sobre el diseño de la cadena productiva local Turismo de Naturaleza: Parque Nacional Turquino, Cuba. Retos Turísticos No 14, La Habana.

Domínguez, L. (1994) Relevamiento turístico. Gestión Turística del Patrimonio Cultural. La Habana: Félix Varela.

Del Risco, Y. (2002) Turismo en áreas naturales sensibles y sustentablidad, Turismo y Sustentabilidad: Un acercamiento multidisciplinar para el análisis del movimiento y de las estrategias de planificación territorial, Italia: Brigati.

Díaz, B. (2011) Diseño de productos turísticos. Madrid; Síntesis.

Hosteltur (2005) Turismo Cultural. Disponible en: https:/ /www.hostel tur.com/ edicion-impresa/turismocultural

Fennell, D. (1999) Ecotourism: An introduction. London: Routledge.

Maribona, A. (1959) Turismo en Cuba. La Habana: Lex.

Martín Mateo, R. (1985) Derecho Público de la Economía. España: CEURA.

Martín, R. (2003) Manual de Teoría y Práctica del Turismo, Universidad de La Habana. 
SÁNCHEZ, Alcides Antúnez; VÁZQUEZ, Ana Elisa Gorgoso. El ecoturismo, influencia en el desarrollo sociocultural del municipio. Revista Eletrônica Direito e Política, Programa de Pós-Graduação Stricto Sensu em Ciência Jurídica da UNIVALI, Itajaí, v.16, n.2, $2^{\circ}$ quadrimestre de 2021. Disponível em: www.univali.br/direitoepolitica - ISSN 1980-7791.

Melgosa Arcos, F. (2002) La ordenación de los campamentos de turismo y de las acampadas. Ordenación y gestión del territorio turístico Valencia: Tirant lo Blanch.

González, L. (1999) Turismo ecológico en Cuba. Mil paisajes para admirar, Excelencias Turísticas del Caribe, № 12, Madrid, pp.28-29.

Gorgoso Vázquez, A. y Antúnez Sánchez, A. (2021) El Derecho Cultural en el ordenamiento jurídico cubano $(\mathrm{s} / \mathrm{p})$

Torres Pérez, R. (2011) La actualización del modelo económico cubano, reconfiguración del sistema económico cubano, el reconocimiento y legitimidad a las formas de gestión no estatal, Revista Temas, La Habana.

Sanz Domínguez, C. (2005) Régimen jurídico-administrativo de la intermediación turística.

España: Conserjería de Turismo, Comercio y Deporte.

Sancho A. (1998) Introducción al turismo, España: OMT.

Sandoval, E. (2007) Ecoturismo: Operación Técnica y Gestión Ambiental. México: Trillas.

Salinas, E. et. al (2008) Apuntes geografía turística de Cuba. La Habana: Félix Varela.

Sánchez, M. y Fajardo, M. (2004) La competitividad de los destinos turísticos: un análisis cuantitativo mediante modelos logísticos. Aplicación a los municipios extremeños. España: Universidad de Extremadura.

Simancas Cruz, M. et al. (2016) La planificación y gestión territorial del turismo. Madrid: Síntesis.

Ros Development \& Planning S. (2008) Modelos de gestión turística local. Principios y prácticas. Madrid: Federación Española de Municipios y ProvinciasSecretaría General de Turismo. 
SÁNCHEZ, Alcides Antúnez; VÁZQUEZ, Ana Elisa Gorgoso. El ecoturismo, influencia en el desarrollo sociocultural del municipio. Revista Eletrônica Direito e Política, Programa de Pós-Graduação Stricto Sensu em Ciência Jurídica da UNIVALI, Itajaí, v.16, n.2, $2^{\circ}$ quadrimestre de 2021. Disponível em: www.univali.br/direitoepolitica - ISSN 1980-7791.

Rivera Mateo, M. et al. (2012) Turismo responsable, sostenibilidad y desarrollo local comunitario. España: Universidad de Córdova.

Organización Mundial del Turismo (2000) Turismo sostenible y gestión municipal. Madrid.

Organización Mundial del Turismo (2002) Guía para administraciones locales: desarrollo turístico sustentable y sostenible. Madrid.

Organización Mundial del Turismo (2017) Ecotourism and protected areas. Disponible en: http://sdt.unwto.org/content/ecotourism-and-protected-areas

Ortiz, F. (1983) Del fenómeno social de la transculturación y de su importancia en Cuba. Contrapunteo cubano del tabaco y el azúcar. La Habana: Ciencias Sociales.

Ramírez, C. (2006) Visión Integral del Turismo. México: Trillas.

Ramírez Sánchez, A. y Antúnez Sánchez, A. (2018) El régimen jurídico de la inspección administrativa y los derechos sociales en Cuba. Apuntes para una reforma. Revista Derecho y Paz No. 38. Brasil.

Pérez Gallardo, L. (2011) Cultura y cultura popular. Influencia recíproca: África, España, Francia, China e Iberoamérica. El derecho como saber cultural. La Habana: Universidad de La Habana.

Pulido Fernández, J. (2013) Turismo cultural, España: Síntesis.

Le Riverend, J. (1983) Estudio preliminar. Contrapunteo cubano del tabaco y el azúcar. La Habana: Ciencias Sociales.

Weaver, D. (2001) The Encyclopedia of Ecotourism. Wallingford: CAB International Publishing.

Vandeli, L. (2018) Ordenación jurídico administrativa del Turismo. España: Atelier.

Villalba Garrido, E. (1994) Cuba y el turismo. La Habana: Ciencias Sociales. 
SÁNCHEZ, Alcides Antúnez; VÁZQUEZ, Ana Elisa Gorgoso. El ecoturismo, influencia en el desarrollo sociocultural del municipio. Revista Eletrônica Direito e Política, Programa de Pós-Graduação Stricto Sensu em Ciência Jurídica da UNIVALI, Itajaí, v.16, n.2, $2^{\circ}$ quadrimestre de 2021. Disponível em: www.univali.br/direitoepolitica - ISSN 1980-7791.

\section{NORMAS JURÍDICAS}

Constitución de la República de Cuba. Gaceta Oficial 2019.

Ley No. 1 de Protección al Patrimonio cultural. G.O.

Ley No. 81 del Medio Ambiente, G. O. Extraordinaria No. 7 de II de julio de 1997

Decreto Ley No. 84. Gaceta Oficial de la República de Cuba. Diciembre de 1999.

Ley No. 113, Ley del Sistema Tributario en Gaceta Oficial No. 053 Ordinaria de 21 de noviembre de 2012

Ley No. 116 Código de Trabajo, en Gaceta Oficial Extraordinaria No. 29 Extraordinaria de 17 de junio de 2014

Decreto Ley No. 201. Sistema de Área Protegida. Gaceta Oficial 24 de noviembre de 1999.

Decreto Ley No. 200. De las contravenciones en Materia de Medio Ambiente. Gaceta Oficial de 12 de diciembre de 1999.

Decreto No 100, Reglamento General de la Inspección Estatal en Gaceta Oficial Ordinaria No 14 de 10 de febrero de 1984

Resolución No. 48 de 2014 MINTUR, Reglamento del buceo recreativo. Gaceta Oficial Ordinaria No. 19 de 8 de mayo 2014.

Resolución No. 49 de 2014 MINTUR, Reglamento sobre los Puntos Náuticos. Gaceta Oficial Ordinaria No. 19 de 8 de mayo 2014.

Resolución No. 50 de 2014 MINTUR, principios y procedimientos para la aprobación de los productos turísticos de naturaleza, de aventuras y rural en el territorio nacional. Gaceta Oficial Ordinaria No. 19 de 8 de mayo 2014.

RECEBIDO EM: MAI/2021

APROVADO EM: JUL/2021 